Check for updates

Cite this: RSC Adv., 2019, 9, 7338

Received 19th December 2018 Accepted 27th February 2019

DOI: $10.1039 / c 8 r a 10385 b$

rsc.li/rsc-advances

\section{Microscale flower-like magnesium oxide for highly efficient photocatalytic degradation of organic dyes in aqueous solution $\uparrow$}

\author{
Yajun Zheng, ${ }^{\text {ab }}$ Liyun Cao, $^{\text {a }}$ Gaoxuan Xing, ${ }^{\text {b } Z o n g q u a n ~ B a i, ~}{ }^{b}$ Jianfeng Huang ${ }^{a}$ \\ and Zhiping Zhang (D)*b
}

Flower-like $\mathrm{MgO}$ microparticles with excellent photocatalytic performance in degradation of various organic dyes (e.g., methylene blue, Congo red, thymol blue, bromothymol blue, eriochrome black $\mathrm{T}$, and their mixture) were synthesized by a facile precipitation method via the reaction between $\mathrm{Mg}^{2+}$ and $\mathrm{CO}_{3}{ }^{2-}$ at $70{ }^{\circ} \mathrm{C}$. The reaction time was found to be crucial in determining the final morphology of flower-like $\mathrm{MgO}$. After studying the particles from time-dependent experiments, scanning electron microscope observation, Fourier transform infrared spectra and thermogravimetric analyses demonstrated that the formation of flower-like particles involved a complex process, in which agglomerates or rod-like particles with a formula of $x \mathrm{MgCO}_{3} \cdot y \mathrm{H}_{2} \mathrm{O}(x=0.75-0.77$ and $y=1.87-1.96)$ were favorably formed after the initial mixture of the reactants. Owing to the chemical instability, they would turn into flower-like particles, which had a composition of $x \mathrm{MgCO}_{3} \cdot y \mathrm{Mg}(\mathrm{OH})_{2} \cdot z \mathrm{H}_{2} \mathrm{O}(x=0.84-$ $0.86, y=0.13-0.23$, and $z=0.77-1.15)$. After calcination, the generated product not only possessed a superior photocatalytic performance in degradation of organic dyes $\left(100 \mathrm{mg} \mathrm{L}^{-1}\right)$ under UV light irradiation in contrast to other morphologies of $\mathrm{MgO}$ and other related state-of-the-art photocatalysts (e.g., $\mathrm{N}$-doped $\mathrm{TiO}_{2}$, Degussa $\mathrm{P} 25 \mathrm{TiO}_{2}, \mathrm{ZnO}, \mathrm{WO}_{3}, \alpha-\mathrm{Fe}_{2} \mathrm{O}_{3}, \mathrm{BiVO}_{4}$, and $\mathrm{g}-\mathrm{C}_{3} \mathrm{~N}_{4}$ ), but also could be used for five cycles, maintaining its efficiency above $92.2 \%$. These capacities made the flower-like $\mathrm{MgO}$ a potential candidate for polluted water treatment. Also, the underlying photocatalysis mechanism of $\mathrm{MgO}$ was proposed through radical trapping experiments.

\section{Introduction}

Organic dyes, being discharged from the textile, food, cosmetics, and pharmaceutical industries, are a class of harmful pollutants, ${ }^{1}$ and pose a series of threats to public health and ecological systems because of their toxicity and accumulation. To date, various biological, physical, and chemical protocols have been developed to handle dye-contaminated effluents. Biological methods are environmentally friendly and retain the quality of environments in the remediation process, ${ }^{2,3}$ whereas the related techniques are often costly, ineffective and nondestructive to organic pollutants. Traditional physical techniques such as adsorption have demonstrated superior performance in removal of organic dyes from aqueous solution, ${ }^{4,5}$ but they require an extra and tedious treatment after adsorption for

${ }^{a}$ School of Material Science and Engineering, Shaanxi University of Science and Technology, Xi'an 710021, China.E-mail: caoliyun@sust.edu.cn

${ }^{b}$ School of Chemistry and Chemical Engineering, Xi'an Shiyou University, Xi'an 710065, China. E-mail: zhangzp0304@gmail.com; Fax: +86 298838 2693; Tel: +86 2988382694

† Electronic supplementary information (ESI) available. See DOI: $10.1039 / \mathrm{c} 8 \mathrm{ra10385b}$ regeneration of used adsorbents. Degradation of organic dyes in industrial effluents through chemical remediation has also received tremendous attention on account of its immense applications. Among the developed methods, photocatalytic degradation using renewable UV/sun light is one of the most promising techniques owing to its simplicity and costeffectiveness. $^{6-8}$

Numerous metal oxides (e.g., $\mathrm{TiO}_{2},{ }^{9} \mathrm{ZnO},{ }^{10} \mathrm{Fe}_{2} \mathrm{O}_{3}{ }^{11}$ and $\mathrm{WO}_{3}{ }^{12}$ ), owing to their high chemical stability, nontoxicity, high activity, and low cost, have been extensively used as photocatalytic materials for degradation of organic dyes, and their catalytic mechanisms have also been well documented. ${ }^{\mathbf{1 3}}$ Magnesium oxide ( $\mathrm{MgO})$, as a versatile oxide material, has found widespread applications in the fields of adsorption, ${ }^{5}$ catalysis, ${ }^{\mathbf{1 4}}$ ceramics, ${ }^{\mathbf{1 5}}$ antibacterial materials, ${ }^{16}$ paint, ${ }^{17}$ and superconductor products. ${ }^{18}$ Some attempts ${ }^{19-26}$ have also been made to employ $\mathrm{MgO}$ as a photocatalyst for degradation of various dyes in aqueous solution based on its large band gap, low dielectric constant and refractive index. For example, Demirci and colleagues ${ }^{27}$ studied the photocatalytic degradation rate of methylene blue solution $\left(6 \times 10^{-6} \mathrm{M}, 1.9 \mathrm{mg} \mathrm{L}^{-1}\right)$ under the catalysis of nanoscale $\mathrm{MgO}$ by means of flame spray pyrolysis and sol-gel techniques. Both types of generated $\mathrm{MgO}$ 
particles demonstrated comparable activity for the degradation of methylene blue, and the degradation efficiencies were 94\% and $90 \%$ after $240 \mathrm{~min}$, respectively. Mantilaka et al. ${ }^{26}$ reported that in contrast to $\mathrm{MgO}$ nanospheres, electrospun $\mathrm{MgO}$ nanofibers demonstrated a more complete degradation efficiency to reactive yellow (10 ppm) after $40 \mathrm{~min}$. Mageshwari et al. ${ }^{20}$ investigated the photocatalytic activity of flakes-like $\mathrm{MgO}$ nanoparticles synthesized by a reflux condensation method, and found that $99.14 \%$ of degradation efficiency could be obtained for $15 \mathrm{mg} \mathrm{L}^{-1}$ of methyl orange and methylene blue dyes after an irradiation period of $240 \mathrm{~min}$. Salehifar et al. ${ }^{24}$ synthesized $\mathrm{MgO}$ nanorods via a thermal decomposition route, and observed this material exhibiting appreciable photocatalytic activity, and $90 \%$ degradation of methylene blue $\left(25 \mathrm{mg} \mathrm{L}^{-1}\right.$ ) was obtained after $180 \mathrm{~min}$. Kumara et al. ${ }^{23}$ reported the catalytic activity of $\mathrm{MgO}$ nanoparticles generated from low temperature $\left(400{ }^{\circ} \mathrm{C}\right)$ solution combustion method using urea as fuel, and $98 \%$ and $91 \%$ of methylene blue and methyl orange with a concentration of $60 \mathrm{mg} \mathrm{L}^{-1}$ were degraded after a period of $60 \mathrm{~min}$, respectively. Those studies are crucial to better understanding of the feasibility of using $\mathrm{MgO}$ as a photocatalyst for degrading organic dyes. But they are mainly limited in nanoscaled particles, which makes it a challenge for the following recycle and regeneration due to small particle sizes. In addition, the concentration of organic dyes for photocatalytic degradation in the literature is generally in the range of $1.9-60 \mathrm{mg} \mathrm{L}^{-1}$, not suitable for wastewater with high concentrations of organic dyes. Therefore, it is necessary to develop larger sized $\mathrm{MgO}$ (e.g., micro-sized particles) with high efficiency in degradation of organic dyes.

Over the past decades, different protocols, including chemical vapor deposition, ${ }^{28}$ hydrothermal approach, ${ }^{29}$ sol-gel route $^{30}$ and precipitation,,$^{31}$ have been developed for preparing $\mathrm{MgO}$ particles. Amongst them, precipitation has received considerable attentions due to its unique features such as facile large-scale production, cost-effectiveness and avoidance of organic reagents. In the previous studies, ${ }^{\mathbf{1 4 , 3 2 - 3 5}}$ we found that various morphologies of micro-sized $\mathrm{MgO}$ could be synthesized by precipitation. Inspired by those investigation, herein we developed a micro-sized flower-like $\mathrm{MgO}$, and explored its shape and composition evolution with reaction time. The photocatalytic performance of the as-synthesized $\mathrm{MgO}$ was evaluated by monitoring the photodegradation of various organic dyes (e.g., methylene blue, Congo red, thymol blue, bromothymol blue, eriochrome black $\mathrm{T}$, and their mixture) under UV light irradiation. In contrast to other available micro-sized $\mathrm{MgO}$ with different morphologies (e.g., nest-like, spherical, rod-like and trapezoidal products), the as-prepared flower-like material illustrated a superior performance, and $100 \mathrm{mg} \mathrm{L}^{-1}$ of organic dyes such as methylene blue in aqueous solution could be completely degraded in $90 \mathrm{~min}$. Several techniques, including photoluminescence spectroscopy, UV diffused reflectance spectroscopy, $\mathrm{N}_{2}$ physical adsorption and UV-visible spectrometer, were also used to explore the differences between the surface properties of various morphologies of $\mathrm{MgO}$ in detail. The underlying photocatalysis mechanism of $\mathrm{MgO}$ was also proposed.

\section{Experimental}

\subsection{Synthesis of flower-like MgO}

All reagents (e.g., $\mathrm{Mg}\left(\mathrm{NO}_{3}\right)_{2} \cdot 6 \mathrm{H}_{2} \mathrm{O}$ and $\left.\mathrm{Na}_{2} \mathrm{CO}_{3}\right)$ were of analytical grade or better and were used as received without further purification. The procedure was similar to our previous report ${ }^{\mathbf{1 4}}$ but had a different stirring condition. Specifically, $0.04 \mathrm{~mol}$ of $\mathrm{Mg}\left(\mathrm{NO}_{3}\right)_{2} \cdot 6 \mathrm{H}_{2} \mathrm{O}$ (Guangdong Guanghua Sci-Tech Co., Ltd., Shantou, China) was dissolved into $50 \mathrm{~mL}$ of deionized water, followed by transferring into a $250 \mathrm{~mL}$ three-necked flask and heated to $70{ }^{\circ} \mathrm{C}$. Under the vigorous stirring ( $c a .1000 \mathrm{rpm}$ ), $100 \mathrm{~mL}$ of $0.4 \mathrm{M} \mathrm{Na}_{2} \mathrm{CO}_{3}$ (Tianjin Tianli Chemical Reagents Co., Ltd., Tianjin, China) solution was poured into the $\mathrm{Mg}\left(\mathrm{NO}_{3}\right)_{2}$ solution in $10 \mathrm{~s}$, which was then stirred for $3 \mathrm{~min}$. Afterwards, the mixture was maintained at $70{ }^{\circ} \mathrm{C}$ for $1 \mathrm{~h}$ under static conditions, and the obtained product was collected, filtered off, and washed with deionized water for three times (each with around $110 \mathrm{~mL}$ and a washing time of about 50 seconds) followed by $20 \mathrm{~mL}$ of absolute ethanol. The flower-like $\mathrm{MgO}$ sample was fabricated by calcining the obtained product in air from room temperature to $550{ }^{\circ} \mathrm{C}$ in a muffle furnace, and then maintaining at that temperature for $3 \mathrm{~h}$.

\subsection{Catalyst characterization}

The morphology and size of the obtained particles were examined by a JEOL JSM-6390A scanning electron microscope (SEM). The crystal structures of the as-synthesized products were characterized by X-ray diffraction (XRD) on a XRD-6000 diffractometer using $\mathrm{Cu} \mathrm{K} \alpha$ radiation. The operation voltage was $40 \mathrm{kV}$, and the current was $30 \mathrm{~mA}$. The microstructure and crystalline structure of flower-like $\mathrm{MgO}$ particles was analyzed by transmission electron microscope (TEM, JEOL JEM-2100 Plus) with an acceleration voltage of $200 \mathrm{kV}$. Optical band gaps of $\mathrm{MgO}$ particles with different morphologies were estimated from UV diffused reflectance spectroscopy (DRS) using a UV-2600 UV-vis spectrophotometer. The optical band gap of $\mathrm{MgO}$ particles was calculated according to the previously reported method. ${ }^{20}$ Photoluminescence (PL) spectra were recorded using a Thermo Scientific Lumina spectrofluorometer equipped with $150 \mathrm{~W}$ xenon lamp (excitation wavelength $=325$ $\mathrm{nm})$. The thermal decomposition behaviors of the $\mathrm{MgO}$ precursors were detected by a thermogravimetric analyzer (TGA, Mettler Toledo, TGA/DSC1 STAR System, Switzerland), which was carried out in dynamic nitrogen gas with a heating rate of $10{ }^{\circ} \mathrm{C} \min ^{-1}$. The $\mathrm{N}_{2}$ adsorption-desorption isotherm was determined on a Micromeritics ASAP 2020HD88 physisorption apparatus at the temperature of liquid nitrogen, in which the samples were degassed at $350{ }^{\circ} \mathrm{C}$ for $4 \mathrm{~h}$ before measurement. The surface area was calculated by the Brunauer-Emmett-Teller (BET) method. The concentration of methylene blue in aqueous solutions was measured on a Shimadzu UV-2600 UV-visible spectrometer.

\subsection{Photocatalytic activity}

The photocatalytic performance of the as-prepared $\mathrm{MgO}$ particles, N-doped $\mathrm{TiO}_{2}$ and $\mathrm{ZnO}$ (Hangzhou Zhitai Purification 
Technology Co., Ltd., Hangzhou, China), $\mathrm{WO}_{3}$ (Shanghai Yuanye Bio-Technology Co., Ltd., Shanghai, China), $\alpha-\mathrm{Fe}_{2} \mathrm{O}_{3}$ (Shanghai Yi'en Chemical Technology Co., Ltd., Shanghai, China), $\mathrm{BiVO}_{4}$ (Sa'en Chemical Technology Co., Ltd., Shanghai, China), g- $\mathrm{C}_{3} \mathrm{~N}_{4}$ (Jiangsu XFNANO Materials Tech Co., Ltd., Nanjing, China), and Degussa P25 $\mathrm{TiO}_{2}$ nanoparticles (Shanghai Bestmore Industry Co. Ltd., Shanghai, China) was evaluated by monitoring the photodegradation of organic dyes such as methylene blue under UV light irradiation with a mercury lamp (power: $400 \mathrm{~W}$, wavelength: $365 \mathrm{~nm}$ ). In a typical process, $10 \mathrm{mg}$ of $\mathrm{MgO}$ particles were added into $20 \mathrm{~mL}$ of methylene blue solution with a concentration of $100 \mathrm{mg} \mathrm{L}^{-1}$. The distance between the lamp and the suspension containing $\mathrm{MgO}$ particles was $15 \mathrm{~cm}$. After the mixture was irradiated with UV radiation under gently magnetic stirring for $90 \mathrm{~min}$, the generated suspension was taken and centrifuged $(8000 \mathrm{rpm}$ for $6 \mathrm{~min}$ ) to separate the reaction solution and the $\mathrm{MgO}$ photocatalyst. Then the supernatant was analyzed by a Shimadzu UV2600 UV-visible spectrometer. For the recycle and regeneration of flower-like $\mathrm{MgO}$ particles, the collected catalyst was first heated to $400{ }^{\circ} \mathrm{C}$ and then maintained at that temperature for $3 \mathrm{~h}$ in a nitrogen atmosphere followed by calcination at $550{ }^{\circ} \mathrm{C}$ for $3 \mathrm{~h}$ in air following our recent study. ${ }^{14}$

The degradation efficiency of studied dye on $\mathrm{MgO}$ was evaluated using eqn (1), ${ }^{36}$ and the photocatalytic kinetic was characterized by eqn (2). ${ }^{20}$

$$
\begin{gathered}
\text { Degradation efficiency }=\frac{C_{0}-C}{C_{0}} \times 100 \% \\
\ln \frac{C_{0}}{C}=k t
\end{gathered}
$$

where $C_{0}$ is the initial concentration of dye solution, $C$ is the concentration of dye solution after irradiation in a fixed interval, $k$ is the degradation rate constant, and $t$ is the reaction time (min).

\section{Results and discussion}

\subsection{Synthesis and characterization of flower-like $\mathrm{MgO}$ catalyst}

The flower-like $\mathrm{MgO}$ was synthesized by the reaction between $0.04 \mathrm{M}$ of $\mathrm{Mg}\left(\mathrm{NO}_{3}\right)_{2}$ and $\mathrm{Na}_{2} \mathrm{CO}_{3}$ without addition of any organic or inorganic additives at $70{ }^{\circ} \mathrm{C}$. After mixing, the reaction solution was stirred for $3.0 \mathrm{~min}$ and then maintained under static conditions for $1 \mathrm{~h}$. Fig. $1 \mathrm{a}$ and $\mathrm{b}$ shows the representative SEM images of the as-prepared flower-like MgO particles by calcining their precursors at $550{ }^{\circ} \mathrm{C}$ for $3 \mathrm{~h}$. Fig. 1a presents the lower-magnification SEM image of the synthesized particles. Obviously, the panoramic morphology of the sample consists of flower-like particles with diameters of 3.8-6.0 $\mu \mathrm{m}$. Fig. 1b shows a magnified view of an individual particle, and careful observation could be found that the particle is composed of sheet-like structure with a thickness of 16-20 nm. The purity and crystallinity of the as-synthesized product were examined by using powder XRD (Fig. 1c). All the diffraction peaks could be indexed to a cubic structure of $\mathrm{MgO}$ with a crystallite size of $7.2 \mathrm{~nm}$
(JCPDS no. 45-0946). No other peaks were observed, indicating the high purify of the obtained particles. HRTEM images demonstrate that the flower-like $\mathrm{MgO}$ structure is polycrystalline in nature (Fig. 1d) and is made of domains of single crystalline nanoparticles and amorphous particles (Fig. 1e). These characteristics suggest that the developed $\mathrm{MgO}$ particles have the feature of mesocrystal material, in good agreement with our recent study on parallelogrammic $\mathrm{MgO} .{ }^{34} \mathrm{~N}_{2}$ adsorption-desorption measurement was also carried out to study the surface structure and porosity of generated $\mathrm{MgO}$. As shown in Fig. 1f, a type-IV characteristics with a significant $\mathrm{H} 3$ loop $^{37}$ was observed for $\mathrm{N}_{2}$ adsorption-desorption isotherms. The BJH pore size distribution (inset in Fig. 1f) obtained from the isotherm indicated that the obtained flower-like $\mathrm{MgO}$ possessed hierarchical pore structure including mesopores and macropores. Their pore sizes were centered around $5.2 \mathrm{~nm}$ and $53.5 \mathrm{~nm}$, respectively, in consistance with the $\mathrm{H} 3$ loop in the $\mathrm{N}_{2}$ adsorption-desorption isotherms. From those measurement, the obtained flower-like MgO had a BET specific surface area, pore volume, and average pore diameter of $142.9 \mathrm{~m}^{2} \mathrm{~g}^{-1}, 0.37$ $\mathrm{cm}^{3} \mathrm{~g}^{-1}$ and $8.4 \mathrm{~nm}$ (Table 1), respectively.

To demonstrate the performance of obtained flower-like $\mathrm{MgO}$ in the treatment of polluted water, methylene blue was selected as a model organic pollutant. UV-vis absorption spectroscopy was employed to evaluate the adsorption behavior of the aqueous solution after treatment. The characteristic absorption peak of methylene blue at $664 \mathrm{~nm}$ was used to monitor the removal efficiency of flower-like $\mathrm{MgO}$. To exclude the influences of $\mathrm{MgO}$ adsorption and UV irradiation on the removal, the variation in the concentration of $100 \mathrm{mg} \mathrm{L}^{-1}$ of methylene blue aqueous solution under different experimental conditions was studied in detail as shown in Fig. 1g and S1 (see the ESI $\dagger$ ). For the reaction system without irradiation but with $\mathrm{MgO}$, the concentration of methylene blue after $90 \mathrm{~min}$ of stirring kept constant, suggesting that the flower-like MgO had very weak adsorption ability under the current condition. As the solution was exposed under the UV irradiation but without $\mathrm{MgO}$, it could be found that $23.6 \%$ of methylene blue were photodegraded from the aqueous solution after an irradiation period of $90 \mathrm{~min}$, and the remaining concentration was $76.4 \mathrm{mg} \mathrm{L}^{-1}$. When the as-prepared $\mathrm{MgO}$ particles were involved in the reaction system, the concentration of methylene blue gradually decreased with extension of irradiation time, and 99.8\% of degradation efficiency was obtained after $90 \mathrm{~min}$. Fig. $1 \mathrm{~h}$ compares the color change in $100 \mathrm{mg} \mathrm{L}^{-1}$ of methylene blue solution before and after treatment with the flower-like $\mathrm{MgO}$ under UV irradiation. It is apparent that the assynthesized $\mathrm{MgO}$ is a highly efficient catalyst for the degradation of methylene blue in aqueous solution. We also found that it was an excellent catalyst in degradation of other dyes such as Congo red, thymol blue, bromothymol blue, and eriochrome black T. Fig. 2a-d shows that when $100 \mathrm{mg} \mathrm{L}^{-1}$ of the above dye solution was treated with the as-synthesized $\mathrm{MgO}$, respectively, the degradation efficiency could be more than $99.9 \%$. In the real wastewater, dye generally exits as a mixture rather than a single one. To explore the capacity of the developed $\mathrm{MgO}$, we treated the mixture solution containing the above dyes as well as 

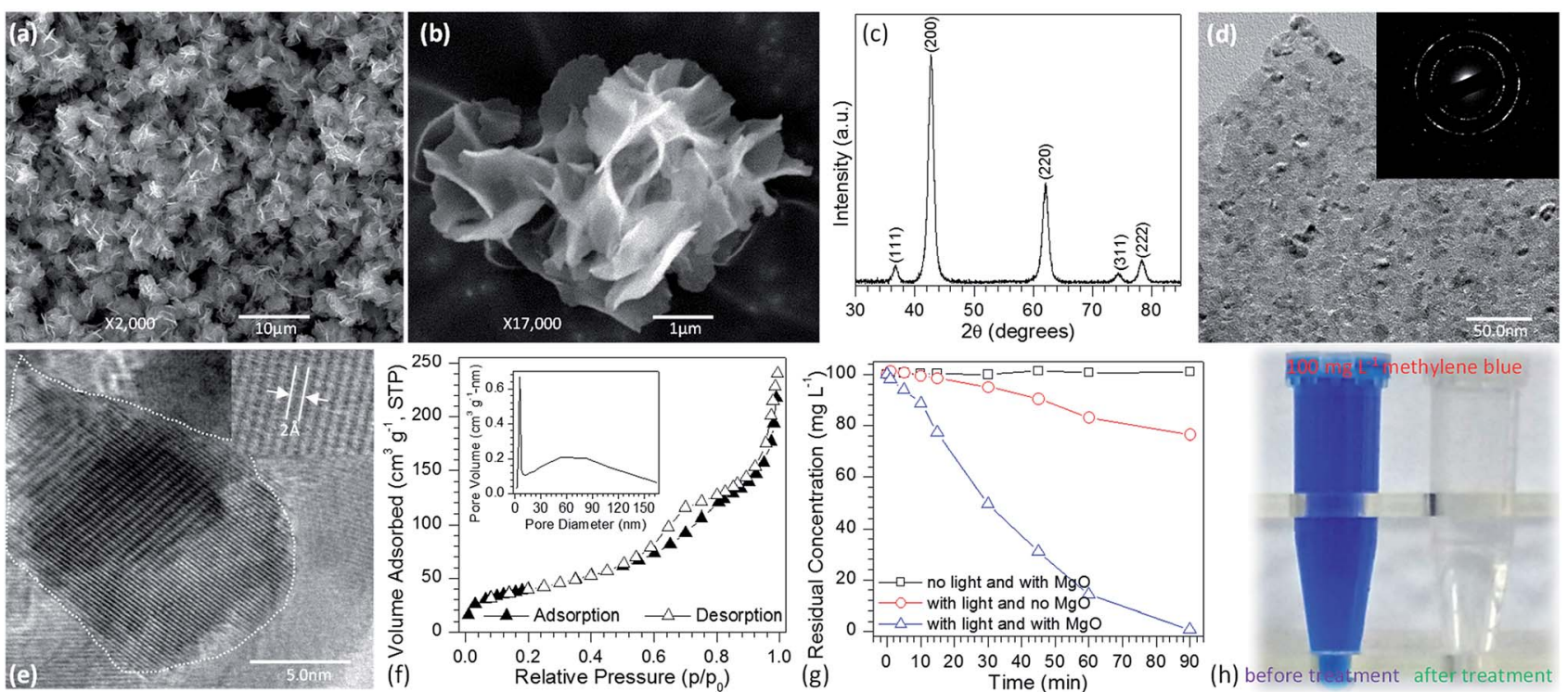

Fig. 1 Representative SEM images of flower-like $\mathrm{MgO}$ particles generated by calcining its precursor which was synthesized by reaction between $\mathrm{Mg}\left(\mathrm{NO}_{3}\right)_{2}$ and $\mathrm{Na}_{2} \mathrm{CO}_{3}$ under a temperature of $70{ }^{\circ} \mathrm{C}$ : (a) panoramic morphology and (b) individual particle; (c) XRD pattern; (d) and (e) HRTEM images of flower-like $\mathrm{MgO}$ [the right upper insets in (d) and (e) are, respectively, their corresponding selected area electron diffraction (SAED) pattern and magnified area of the region of white dot curve]; ( $f$ ) $\mathrm{N}_{2}$ adsorption-desorption isotherms and pore size distribution (inset) of the generated product; (g) photocatalytic degradation of methylene blue by the as-prepared MgO under different conditions as marked; (h) comparison of the color change of $100 \mathrm{mg} \mathrm{L}^{-1}$ methylene blue aqueous solution before and after treatment with the developed $\mathrm{MgO}$.

methylene blue, and their concentrations were all $100 \mathrm{mg} \mathrm{L}^{-1}$. It is noticeable that using the flower-like particles, almost all dyes could be degraded in $90 \mathrm{~min}$, and its efficiency was beyond than 99\% (Fig. 2e). We also observed the performance of the flowerlike $\mathrm{MgO}$ was superior to other related state-of-the-art photocatalysts in the literature (e.g., N-doped $\mathrm{TiO}_{2},{ }^{38}$ Degussa P25 $\mathrm{TiO}_{2}{ }^{39-41} \mathrm{ZnO},{ }^{42} \mathrm{WO}_{3},{ }^{43} \alpha-\mathrm{Fe}_{2} \mathrm{O}_{3},{ }^{44} \mathrm{BiVO}_{4},{ }^{45}$ and $\left.\mathrm{g}-\mathrm{C}_{3} \mathrm{~N}_{4}{ }^{46}\right)$ in degradation of organic dyes under comparable conditions (Fig. 2e, f and S2-S4 in the ESI†). For example, with the developed $\mathrm{MgO}$ as catalyst, more than $80 \%$ of methylene blue $\left(100 \mathrm{mg} \mathrm{L}^{-1}\right.$ ) could be degraded in $15 \mathrm{~min}$, whereas less than $30 \%$ was degraded using $\mathrm{P} 25 \mathrm{TiO}_{2} \cdot{ }^{39-41}$ With the extension of illustration time up to $90 \mathrm{~min}$, the degradation efficiency was more than 99\% using the flower-like $\mathrm{MgO}$, and the value for P25 $\mathrm{TiO}_{2}$ was around $96 \%$ (Fig. 2f, S2 and S3 $\dagger$ ). Moreover, the performance of the flower-like MgO (Fig. 2e) was much better than the available most used photocatalysts (Fig. S4 $\dagger$ ) in treatment of the mixed organic dyes containing methylene blue,
Congo red, thymol blue, bromothymol blue, and eriochrome black $\mathrm{T}$ with each concentration of $100 \mathrm{mg} \mathrm{L}^{-1}$. These results illustrate that the currently developed $\mathrm{MgO}$ is a promising catalyst in photodegradation of organic dyes in aqueous solution.

\subsection{Evolution in the morphology and composition of flower- like MgO precursor}

To well control the shape and structure of the flower-like MgO, it is crucial to get a better understanding on their formation and evolution. Fig. 3 illustrates the typical SEM images of the particles synthesized from various reaction times at $70^{\circ} \mathrm{C}$. It is evident that after stopping stirring the reaction solution containing $\mathrm{Mg}\left(\mathrm{NO}_{3}\right)_{2}$ and $\mathrm{Na}_{2} \mathrm{CO}_{3}$ under $70{ }^{\circ} \mathrm{C}$ (3 min, Fig. 3a), the primary particles tended to form agglomerates built by the fine grains with sizes of 90-100 $\mathrm{nm}$ and rod-like particles with diameters of $0.2-2.1 \mu \mathrm{m}$. As the reaction period was increased to 5 min (Fig. 3b), rod-like particles were obtained, and there were

Table 1 Texture properties of various morphologies of $\mathrm{MgO}$ particles

\begin{tabular}{lccccc}
\hline Morphology & Specific surface area ${ }^{a}\left(\mathrm{~m}^{2} \mathrm{~g}^{-1}\right)$ & Average pore diameter $^{b}(\mathrm{~nm})$ & $\begin{array}{l}\text { Pore volume } \\
\left(\mathrm{cm}^{3} \mathrm{~g}^{-1}\right)\end{array}$ & Crystallite size $^{c}(\mathrm{~nm})$ & Band gap energy $^{d}\left(\mathrm{eV}^{2}\right)$ \\
\hline Flower-like & 142.9 & 8.4 & 0.37 & 7.2 & 5.23 \\
Nest-like & 141.8 & 11.3 & 0.49 & 8.1 & 5.11 \\
Spherical & 136.1 & 12.3 & 0.58 & 8.2 & 5.01 \\
Rod-like & 137.8 & 5.9 & 0.31 & 5.15 \\
Trapezoidal & 31.8 & 19.5 & 0.13 & 23.1 & 4.99
\end{tabular}

${ }^{a}$ Using the standard Brunauer-Emmett-Teller (BET) method. ${ }^{b}$ Using the Barrett-Joyner-Halenda (BJH) method. ${ }^{c}$ Using the Debye-Scherrer formula based on the full width at half-maximum (fwhm) of the (200) plane. ${ }^{d}$ Estimated from UV diffused reflectance spectroscopy (DRS). 

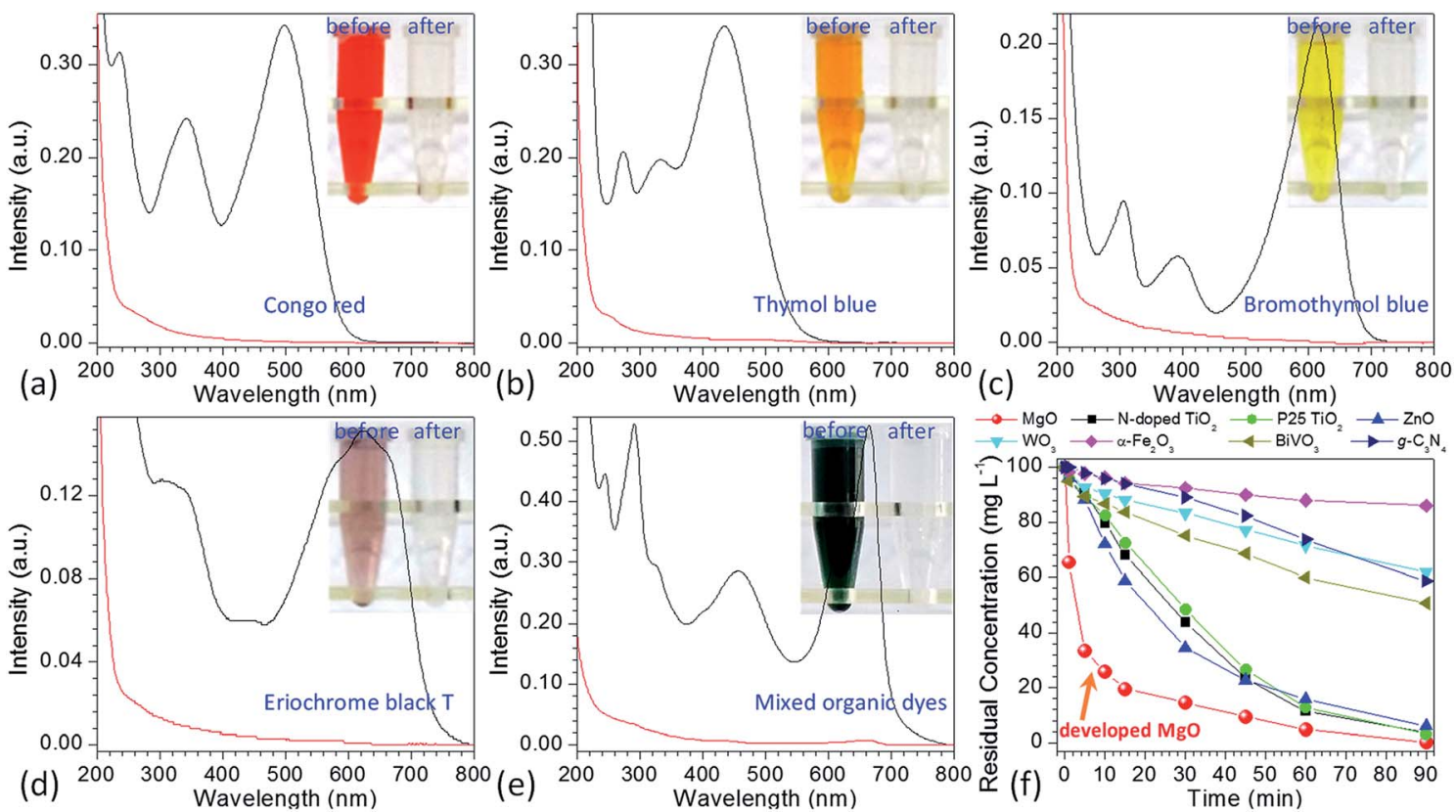

Fig. 2 UV-vis spectra of initial (a) Congo red $\left(100 \mathrm{mg} \mathrm{L}^{-1}\right)$, (b) thymol blue (100 $\left.\mathrm{mg} \mathrm{L}^{-1}\right)$, (c) bromothymol blue (100 $\left.\mathrm{mg} \mathrm{L}^{-1}\right)$, (d) eriochrome black $\mathrm{T}\left(100 \mathrm{mg} \mathrm{L}^{-1}\right)$, (e) their mixed solution plus methylene blue (the concentration of each dye was $100 \mathrm{mg} \mathrm{L}^{-1}$ ) being treated with $10 \mathrm{mg}$ of the asprepared $\mathrm{MgO}$ particles ( - means the solution before treatment, and - means the solution after treatment; irradiation time: 90 min; solution volume: $20 \mathrm{~mL}$; insets are the photographic images of the corresponding solutions after 0 min and 90 min), (f) comparison of the kinetic curves for the degradation of $100 \mathrm{mg} \mathrm{L}^{-1}$ methylene blue between developed $\mathrm{MgO}$ particles and the available state-of-the-art photocatalysts as indicated in this figure.

some flower-like particles involved in the product. More interesting was that there were some sheet-like particles incubating at the surface of generated rod-like particles as indicated in red arrow, which could be the primary unit for flower-like particles. Further increasing the reaction time to $10 \mathrm{~min}$ led to the gradual disappearance of rod-like particles, and promoted the generation of flower-like particles. From Fig. 3c, it is apparent that there are few rod-like particles in the sample, and most of them are flower-like particles. With extension of the reaction period up to 15-60 min (Fig. 3d-f), only flower-like particles were produced although there were some tiny differences between their surface structures, presumably due to their different compositions as discussed below. From the above, it could be envisioned that the formation of flower-like particles experienced a series of complex processes, in which agglomerates were first formed after mixing $\mathrm{Mg}\left(\mathrm{NO}_{3}\right)_{2}$ and $\mathrm{Na}_{2} \mathrm{CO}_{3}$. Due
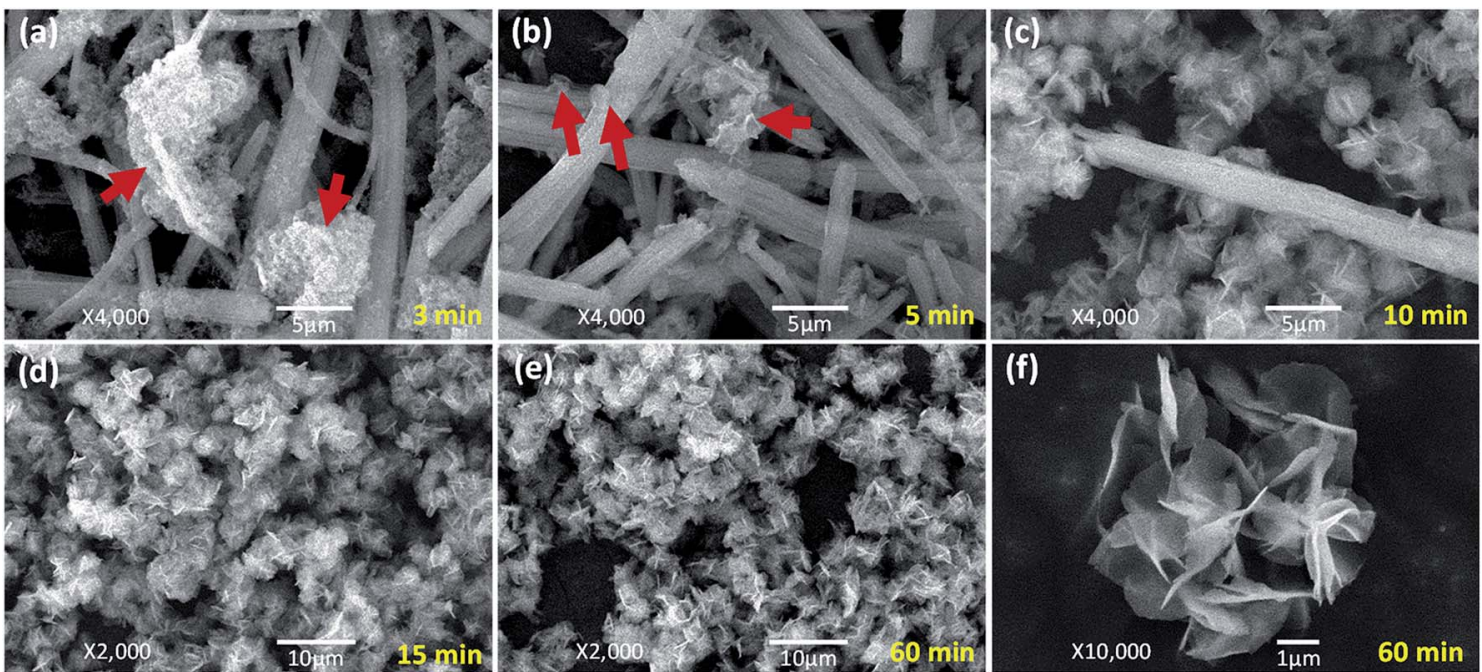

Fig. 3 Typical SEM images of the obtained particles from the reaction between $\mathrm{Mg}\left(\mathrm{NO}_{3}\right)_{2}$ and $\mathrm{Na}_{2} \mathrm{CO}_{3}$ under a temperature of $70{ }^{\circ} \mathrm{C}$ after different reaction periods: (a) $3 \mathrm{~min}$, (b) $5 \mathrm{~min}$, (c) $10 \mathrm{~min}$, (d) $15 \mathrm{~min}$, (e) and (f) $60 \mathrm{~min}$. 
to the thermal instability, ${ }^{33}$ agglomerates began to transfer into rod-like particles, and the latter further became into flower-like particles with extension of reaction time at $70{ }^{\circ} \mathrm{C}$.

In order to get a better understanding on the shape evolution of flower-like particles, the structures and compositions of the samples from different reaction times (3, 5, 10, 15 and $60 \mathrm{~min}$ ) were characterized by FT-IR and TG-DTG analyses. Fig. 4a shows the typical IR spectra of these particles from various times. It is apparent that the reaction time had a pronounced effect on the composition of the resulting products. As the reaction periods were $3 \mathrm{~min}$ and $5 \mathrm{~min}$, both IR spectra were very similar to those of $\mathrm{MgCO}_{3} \cdot 3 \mathrm{H}_{2} \mathrm{O}^{47}$ with the $\mathrm{CO}_{3}{ }^{2-}$ adsorption bands of $854 \mathrm{~cm}^{-1}$ ( $U_{2}$ mode), $1100 \mathrm{~cm}^{-1}$ ( $\nu_{1}$ mode), 1430, 1480 and $1520\left(U_{3}\right.$ mode) as well as the $\mathrm{O}-\mathrm{H}$ bending mode of water at $1650 \mathrm{~cm}^{-1} \cdot{ }^{32}$ In the range of $2800-3700 \mathrm{~cm}^{-1}$, there is a broad band resulting from different numbers of water of crystallization, and the band at $3560 \mathrm{~cm}^{-1}$ could be attributed to the $\mathrm{O}-\mathrm{H}$ stretching vibration of water. When the reaction period was extended to more than $10 \mathrm{~min}$, the IR spectra of generated products had much differences from those generated from reaction periods of $3 \mathrm{~min}$ and $5 \mathrm{~min}$. The $\mathrm{CO}_{3}{ }^{2-}$ bending vibrations split into three bands at 802,854 , and $883 \mathrm{~cm}^{-1}$, and the triple adsorption bands ranging from 1400 to $1550 \mathrm{~cm}^{-1}$ became only two at 1430 and $1490 \mathrm{~cm}^{-1}$. In addition, the bands between 3600 and $3200 \mathrm{~cm}^{-1}$ became narrower, and a sharp band corresponding to the free $\mathrm{O}-\mathrm{H}$ vibration occurred at $3650 \mathrm{~cm}^{-1}$. According to the previous reports, ${ }^{32,33,48,49}$ the above adsorption bands suggested that the products from a reaction time of more than $10 \mathrm{~min}$ possessed the features of $\mathrm{Mg}_{5}\left(\mathrm{CO}_{3}\right)_{4}(\mathrm{OH})_{2} \cdot 4 \mathrm{H}_{2} \mathrm{O}$. Careful observation could be also seen that with variation in the reaction time from 10 to $60 \mathrm{~min}$, the bands at 3650,1380 , and $600 \mathrm{~cm}^{-1}$ demonstrated an increasing trend, revealing that there were some differences between those structures. To figure out the difference between them, the weight loss in the derivative thermogravimetric (DTG) curves of the samples from different reaction times was divided into different temperature stages $\left[50-290{ }^{\circ} \mathrm{C}\right.$ due to adsorbed or crystal $\mathrm{H}_{2} \mathrm{O}, 223-290{ }^{\circ} \mathrm{C}$ due to $\mathrm{H}_{2} \mathrm{O}$ from decomposition of $\mathrm{Mg}(\mathrm{OH})_{2}$ if there was a peak around $247^{\circ} \mathrm{C}$, 290-520 ${ }^{\circ} \mathrm{C}$ due to $\mathrm{CO}_{2}$ from decomposition of $\mathrm{MgCO}_{3}$, and above $520{ }^{\circ} \mathrm{C}$ due to the formation of $\mathrm{MgO}$ ] as shown in Fig. $4 \mathrm{~b}$. After a calculation from the weight loss in various stages, it is clear that the composition of the samples from different reaction times varied significantly (Fig. 4c). For example, as the reaction time was $3 \mathrm{~min}$, the weight loss in the range of 50$290{ }^{\circ} \mathrm{C}$ was around $35.3 \%$, the weight loss from 290 to $600{ }^{\circ} \mathrm{C}$ was $34.4 \%$, and above $600{ }^{\circ} \mathrm{C}$ the remaining weight was about $30.3 \%$. After a rough calculation by dividing their corresponding molecular weights of $\mathrm{H}_{2} \mathrm{O}$ (18.01), $\mathrm{CO}_{2}$ (44.01) and $\mathrm{MgO}$ (40.30), the product had a simple formula of $0.75 \mathrm{MgCO}_{3}$ $\cdot 1.96 \mathrm{H}_{2} \mathrm{O}$. With extension of the reaction time to $5 \mathrm{~min}$, the composition of resulting product $\left(0.77 \mathrm{MgCO}_{3} \cdot 1.89 \mathrm{H}_{2} \mathrm{O}\right)$ was very similar to that from $3 \mathrm{~min}$, which to a certain degree explained why both IR spectra were close (Fig. 4a). When the reaction time was more than $10 \mathrm{~min}$, the formula of generated samples had an analogous composition but were significantly different from the products from 3 and $5 \mathrm{~min}$. Moreover, the amount of $\mathrm{Mg}(\mathrm{OH})_{2}$ demonstrated a gradual increasing trend, whereas an opposite tendency was observed for their water contents, ranging from $0.85 \mathrm{MgCO}_{3} \cdot 0.13 \mathrm{Mg}(\mathrm{OH})_{2} \cdot 1.15 \mathrm{H}_{2} \mathrm{O}$ to $0.86 \mathrm{MgCO}_{3} \cdot 0.23 \mathrm{Mg}(\mathrm{OH})_{2} \cdot 0.77 \mathrm{H}_{2} \mathrm{O}$. These results suggest that the reaction time was a crucial factor in determining the shapes and compositions of obtained products after mixing $\mathrm{Mg}\left(\mathrm{NO}_{3}\right)_{2}$ and $\mathrm{Na}_{2} \mathrm{CO}_{3}$ at $70{ }^{\circ} \mathrm{C}$. Namely, after the initial mixture of reactants, the product tended to become into agglomerates or rodlike particles (Fig. 3a and b) with a simple formula of $x \mathrm{MgCO}_{3} \cdot y \mathrm{H}_{2} \mathrm{O}(x=0.75-0.77$ and $y=1.87-1.96)$. Owing to the chemical instability, they would turn into flower-like particles with a composition of $x \mathrm{MgCO}_{3} \cdot y \mathrm{Mg}(\mathrm{OH})_{2} \cdot z \mathrm{H}_{2} \mathrm{O}(x=0.84-0.86$, $y=0.13-0.23$, and $z=0.77-1.15)$.

\subsection{Comparison between the performance of flower-like MgO and other morphologies of $\mathrm{MgO}$ in photocatalytic degradation of methylene blue}

To date, various morphologies of micro-sized $\mathrm{MgO}$ have been developed via different protocols. ${ }^{31-35,50-54}$ As reported in many studies, ${ }^{\mathbf{1 4 2 9 , 3 4 , 5 5 - 5 9}}$ the catalytic performance of $\mathrm{MgO}$ was highly dependent on its morphology. To get an insight into the difference between the developed flower-like $\mathrm{MgO}$ and others in photocatalytic degradation of methylene blue, several morphologies (e.g., nest-like, spherical, rod-like and trapezoidal) of $\mathrm{MgO}$ were prepared following the previous
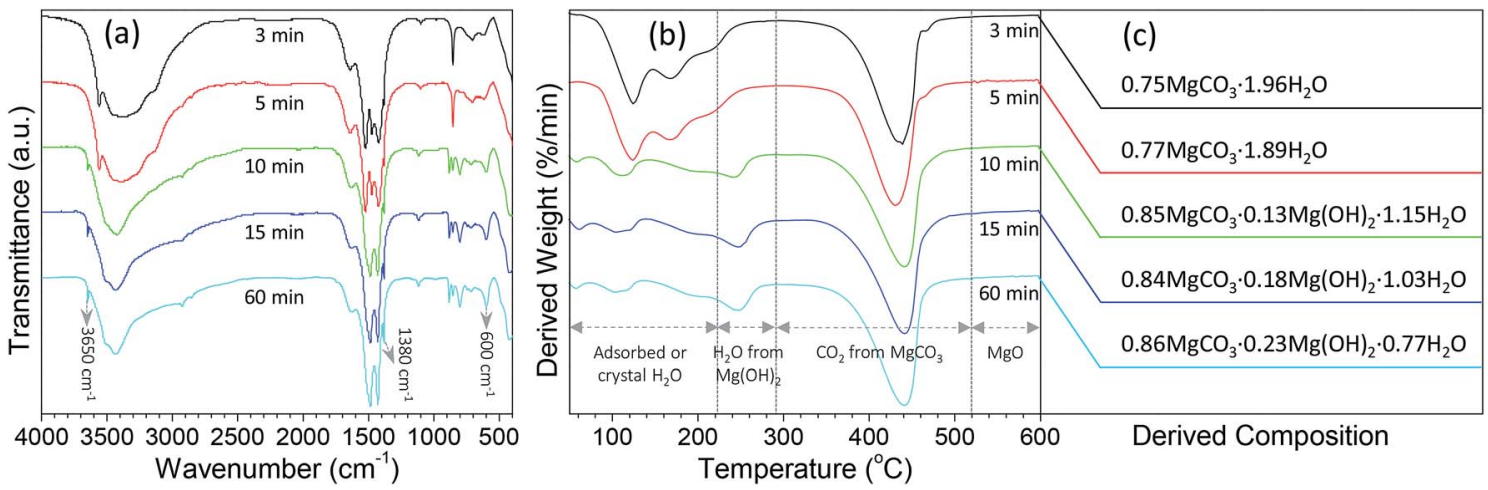

Fig. 4 (a) FT-IR spectra and (b) derivative thermogravimetric (DTG) curves of the particles from the reaction between $\mathrm{Mg}\left(\mathrm{NO}_{3}\right)_{2}$ and $\mathrm{Na}_{2} \mathrm{CO}_{3}$ under a temperature of $70^{\circ} \mathrm{C}$ after various reaction periods, and (c) their derived compositions from thermogravimetric data. 
reports. ${ }^{32-34}$ Their performance was evaluated by the residual concentration of $100 \mathrm{mg} \mathrm{\textrm {L } ^ { - 1 }}$ methylene blue after photocatalytic degradation for $90 \mathrm{~min}$. As shown in Fig. 5a and S5a (see the ESI $\dagger$ ), the catalytic performance of $\mathrm{MgO}$ significantly changed with variation in the morphology, in good agreement with the previous reports. ${ }^{\mathbf{1 4 , 2 9 , 3 4 , 5 5 - 5 9}}$ Among them, flower-like $\mathrm{MgO}$ demonstrated a superior performance to others in degradation of methylene blue, and trapezoidal $\mathrm{MgO}$ gave the poorest capacity. The activity of a catalyst is generally related to their physicochemical properties such as specific surface, average pore, pore volume and crystallite size, but no direct correlation was found between them and the photocatalytic performance of various morphologies of $\mathrm{MgO}$ (Table 1 and Fig. 5a). In addition, little relationship was found between the performance of those $\mathrm{MgO}$ particles and the optical band gap energy (as listed in Table 1) estimated from UV DRS (Fig. S6 in the ESI†). ${ }^{\mathbf{2 0 , 6 0}}$

Although $\mathrm{MgO}$ is a typical wide band gap insulator, its $\mathrm{PL}$ property was generally studied due to the presence of various structural defects (e.g., oxygen vacancies, F-centers or $\mathrm{F}^{+}$centers). ${ }^{61-63}$ According to the report by Mageshwari et al. ${ }^{20}$ a higher abundance of PL emission peaks from $\mathrm{MgO}$ would lead to a more favorable photocatalytic performance. However, an opposite trend was observed for the $\mathrm{MgO}$ with various morphologies in the current investigation despite of the weak PL signal. As shown in Fig. 5b, with varying the $\mathrm{MgO}$ from flower-like to trapezoidal structures, the peak intensity of the PL emission in the range of 350-550 $\mathrm{nm}$ exhibited a gradual increasing trend although the cases for nest-like, spherical and rod-like $\mathrm{MgO}$ were close. A higher intensity in the PL emission, a poor performance in photocatalytic degradation of methylene blue (Fig. 5a). In our opinion, this fact could be ascribed to the different $\mathrm{MgO}$ sizes between the previous report (nano-sized particles) ${ }^{20}$ and the current study (micro-sized particles).

We also observed that the adsorption ability of $\mathrm{MgO}$ was responsible to the photocatalytic degradation of methylene blue in aqueous solution. Fig. $5 \mathrm{c}$ and S5b (see the ESI $\dagger$ ) compared the residual concentration of $50 \mathrm{mg} \mathrm{L}^{-1}$ methylene blue after adsorption with different morphologies of $\mathrm{MgO}$ particles (10 $\mathrm{mg}$ ) for $90 \mathrm{~min}$ without UV light irradiation. It is evident that the developed flower-like $\mathrm{MgO}$ possessed the strongest adsorption ability to methylene blue, followed by nest-like, spherical, rodlike, and trapezoidal MgO. This order is in good agreement with their photocatalytic performance (Fig. 5a). This phenomenon reveals that in the photocatalytic degradation process, the adsorption of methylene blue onto the surface of $\mathrm{MgO}$ plays a crucial role in determining the final catalytic performance. Despite of the less surface defects of the flower-like $\mathrm{MgO}$ relative to others (Fig. 5b), its stronger adsorption ability would make more methylene blue cover at the MgO surface. Under the UV irradiation, methylene blue would more favorably interact with the flower-like $\mathrm{MgO}$, thus leading to its higher efficiency in catalytic degradation.

\subsection{Photocatalytic activity of flower-like MgO}

To evaluate the photocatalytic activity of the developed flowerlike $\mathrm{MgO}$, various concentrations of methylene blue aqueous solutions $\left(25,50,100,200\right.$ and $\left.500 \mathrm{mg} \mathrm{L}^{-1}\right)$ were employed. Fig. 6a shows the degradation kinetic curves of methylene blue with variation in the reaction time ranging from 0 to $90 \mathrm{~min}$ (Fig. S7 in the ESI $\dagger$ ). It is apparent that when the concentration was below than $100 \mathrm{mg} \mathrm{L}^{-1}$, almost all of methylene blue ( $\left.>99 \%\right)$ could be completely degraded in $90 \mathrm{~min}$, and the half-life times $\left(t_{1 / 2}\right)$ for them were $3.47,6.92$ and $24.24 \mathrm{~min}$, respectively (Table $2)$. When the concentration was increased to $200 \mathrm{mg} \mathrm{L}^{-1}$, the catalytic activity of flower-like $\mathrm{MgO}$ was sharply decreased, and only $68.35 \%$ of methylene blue could be degraded after $90 \mathrm{~min}$. Further increasing the concentration of methylene blue up to $500 \mathrm{mg} \mathrm{L}^{-1}$ led to a slower degradation rate, and $18.74 \%$ of degradation efficiency was obtained. Its half-life time was as high as $315.07 \mathrm{~min}$. From the above discussion, it could be seen that the developed flower-like $\mathrm{MgO}$ was an efficient catalyst in degradation of methylene blue with a concentration below than $100 \mathrm{mg} \mathrm{L}^{-1}$, and an increase in the concentration would result in the deterioration of its photocatalytic activity. This could be presumably ascribed to the strong adsorption performance of the flower-like $\mathrm{MgO}$ to methylene blue (Fig. 5c), and the active
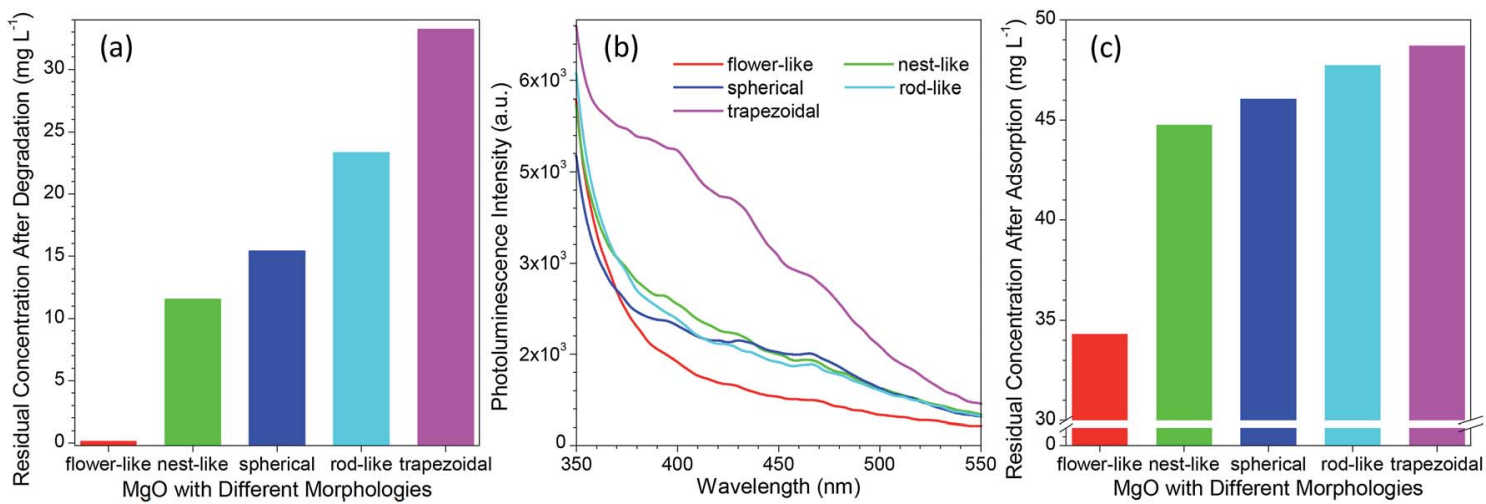

Fig. 5 (a) Comparison of the residual concentration of $100 \mathrm{mg} \mathrm{L}^{-1}$ methylene blue aqueous solution after treatment with different morphologies of $\mathrm{MgO}$ particles; (b) comparison of the photoluminescence spectra of $\mathrm{MgO}$ particles with different morphologies; (c) comparison of the residual concentration of $50 \mathrm{mg} \mathrm{L}^{-1}$ methylene blue aqueous solution after adsorption with different morphologies of $10 \mathrm{mg} \mathrm{MgO}$ particles for 90 min without any UV irradiation. 

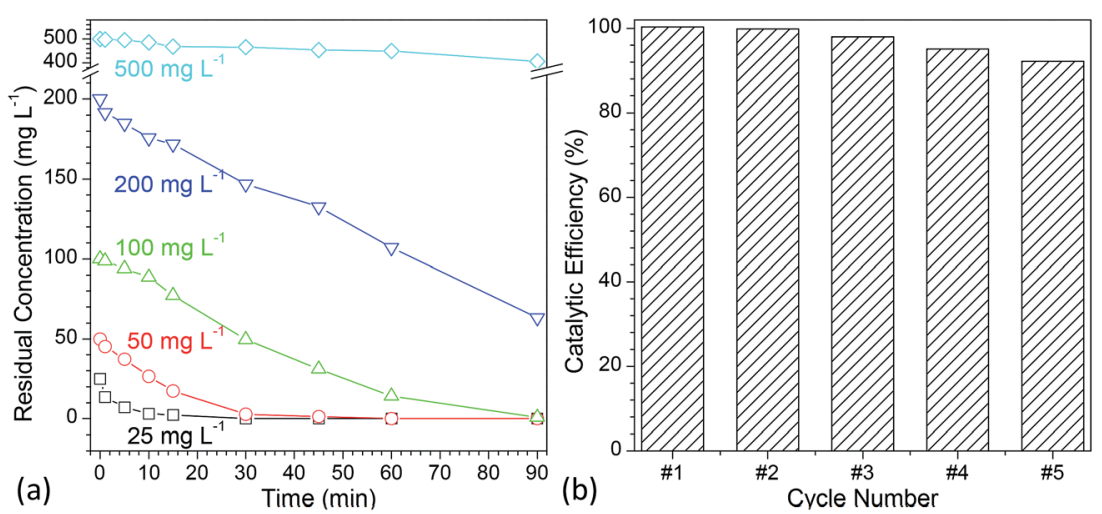

Fig. 6 (a) Comparison of the photocatalytic efficiency of flower-like $\mathrm{MgO}$ with variation in the concentration of methylene blue aqueous solution ranging from 25 to $500 \mathrm{mg} \mathrm{L}^{-1}$ under different irradiation times $(0-90 \mathrm{~min})$; (b) reuse of flower-like $\mathrm{MgO}$ particles for photocatalytic degradation of methylene blue (concentration of methylene blue: $100 \mathrm{mg} \mathrm{L}^{-1}$, irradiation time: $90 \mathrm{~min}$ ).

Table 2 Kinetic parameters of flower-like $\mathrm{MgO}$ for methylene blue degradation

\begin{tabular}{llrrr}
$\begin{array}{l}\text { Concentration } \\
\left(\mathrm{mg} \mathrm{L}^{-1}\right)\end{array}$ & $K_{\mathrm{f}}\left(\mathrm{min}^{-1}\right)$ & $t_{1 / 2}(\mathrm{~min})$ & $R^{2}$ & $\begin{array}{l}\text { Degradation } \\
\text { efficiency }(\%)\end{array}$ \\
\hline 25 & 0.2000 & 3.47 & 0.9639 & 100.00 \\
50 & 0.1001 & 6.92 & 0.9465 & 100.00 \\
100 & 0.0286 & 24.24 & 0.9501 & 99.83 \\
200 & 0.0115 & 60.27 & 0.9670 & 68.35 \\
500 & 0.0022 & 315.07 & 0.9368 & 18.74 \\
\hline
\end{tabular}

sites at its surface were covered by overloaded dye molecules, thus leading to a decrease in its catalytic activity.

In the development of a catalyst, reusability is another important consideration. Although much effort ${ }^{19-26}$ has been made to use $\mathrm{MgO}$ in photocatalytic degradation of various dyes, its reusability is rarely considered. To characterize the reuse of the developed flower-like $\mathrm{MgO}$ particles, $100 \mathrm{mg} \mathrm{L}^{-1}$ methylene blue was degraded with recycled catalyst prepared following a simple centrifugation and calcination procedure. ${ }^{14}$ As shown in Fig. 6b and S8 (see the ESI + ), after five cycles, a degradation efficiency as high as $92.2 \%$ could still be obtained. In the previous studies, ${ }^{\mathbf{1 4 , 6 4 - 7 1}}$ although different shapes of micrometer-sized flower-like $\mathrm{MgO}$ have also been reported, $\mathrm{few}^{66,68,69}$ are analogous to the shape of obtained $\mathrm{MgO}$ in the current study. Also, their performance had much difference. As reported by Cui et al. ${ }^{68}$ the hierarchical flower-like $\mathrm{MgO}$ prepared by their method as a catalyst was fragile, and the petals were prone to break into pieces during stirring. This made their catalytic performance drop sharply after a couple of runs. However, the currently developed flower-like MgO still maintained its capacity after five cycles as described above. We also found that the performance of as-prepared flower-like $\mathrm{MgO}$ was much superior to the flower-like particles ${ }^{14}$ prepared in a comparable condition but with a low stirring speed $(800 \mathrm{rpm}$, Fig. S9 in the ESI $\dagger$ ) although the latter was also composed of nano-sized sheet-like structure and was much more regular in shape than the former. The difference was presumably due to the fact that the currently higher stirring speed $(1000 \mathrm{rpm})$ disturbed the self-assembly behavior of layer-like units into uniform particles, thus leading to a more random sheet-like structure and a higher surface area $\left(142.9 \mathrm{~m}^{2} \mathrm{~g}^{-1}\right)$ than that in the previous study $\left(116.2 \mathrm{~m}^{2} \mathrm{~g}^{-1}\right)^{14}$ despite of comparable crystal structure (Fig. S10†). This promoted a more favorable interaction between the MgO surface and organic dyes in the UV irradiation, and a higher photocatalytic capacity was obtained. Those facts suggest that the currently developed flower-like $\mathrm{MgO}$ is a robust photocatalyst in degradation of methylene blue and other organic dyes in aqueous solution.

\subsection{Possible photocatalytic reaction mechanism}

According to the previous reports, ${ }^{72-77}$ the photocatalytic degradation of organic pollutants occurs mainly through the oxidizability of photogenerated holes $\left(\mathrm{h}^{+}\right)$, hydroxyl radicals $(\cdot \mathrm{OH})$, and superoxide radicals $\left(\cdot \mathrm{O}_{2}^{-}\right)$. For the purpose of better understanding the photocatalytic mechanism of methylene blue over flower-like $\mathrm{MgO}$, the trapping experiments of active species involved in the photocatalytic reaction were investigated. In this study, ammonium oxalate (AO, $\left.5.0 \mathrm{mmol} \mathrm{L}^{-1}\right), t$ butanol (BT, $5.0 \mathrm{mmol} \mathrm{L}^{-1}$ ) and 1,4-benzoquinone (BQ, $\left.0.1 \mathrm{mmol} \mathrm{L}^{-1}\right)$ acting as the scavengers for holes $\left(\mathrm{h}^{+}\right)$, hydroxyl radicals $(\cdot \mathrm{OH})$ and superoxide radicals $\left(\cdot \mathrm{O}_{2}{ }^{-}\right)$were employed. The influence of different scavengers on the degradation efficiency of flower-like $\mathrm{MgO}$ is shown in Fig. 7a. It is obvious that in the presence of $\mathrm{BQ}$, it had less effect on the degradation of methylene blue in the reaction period ranging from 0 to $30 \mathrm{~min}$, and after that (30-90 min) the catalytic reaction had been greatly restricted, suggesting that $\cdot \mathrm{O}_{2}^{-}$active species had a pronounced effect on the photocatalytic performance of developed $\mathrm{MgO}$ as the reaction proceeded for a long period. However, the photocatalytic activity was gradually decreased by adding AO and strongly suppressed by introducing BT. This fact suggests that both $\mathrm{h}^{+}$and $\cdot \mathrm{OH}$ active species played crucial roles in the removal of methylene blue upon the catalysis of flower-like MgO. Based on the above results, it could be concluded that the effect of active species on photocatalytic activities is as follows: $\cdot \mathrm{OH}>\mathrm{h}^{+}>\cdot \mathrm{O}_{2}^{-}$. 

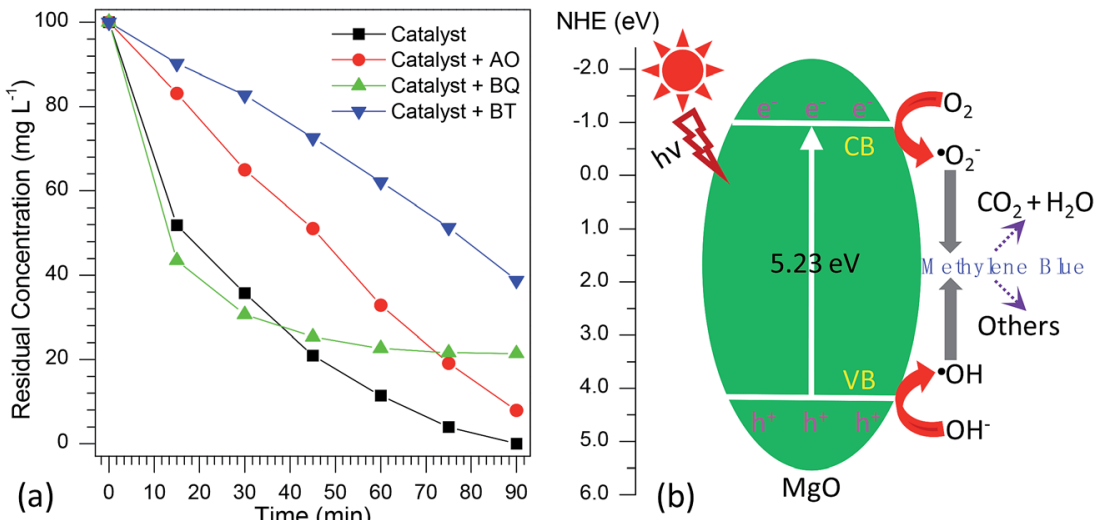

Fig. 7 (a) Effect of different scavengers on the photocatalytic degradation percentage of methylene blue over the developed MgO catalyst (AO means ammonium oxalate, BT means $t$-butanol, and BQ means 1,4-benzoquinone); (b) proposed photocatalytic mechanism for flower-like $\mathrm{MgO}$ under UV light irradiation.

From the above information, a possible mechanism for the degradation of methylene blue over flower-like $\mathrm{MgO}$ is proposed as Fig. 7b. First, the developed $\mathrm{MgO}$ was excited upon the effect of UV light illustration. The electrons on the conduction band (CB) of $\mathrm{MgO}$ with strong reduction ability could drive the generation of superoxide radical anions $\left(\cdot \mathrm{O}_{2}{ }^{-}\right)$through reducing the adsorbed $\mathrm{O}_{2}$ on its surface, whereas the $\mathrm{h}^{+}$on the valence band $(\mathrm{VB})$ of $\mathrm{MgO}$ with high oxidation potentials could produce more reactive $\cdot \mathrm{OH}$ radicals for the photodegradation of methylene blue. As illustrated in the radical trapping experiments, the $\cdot \mathrm{OH}$ and $\mathrm{h}^{+}$were the dominant species for attacking methylene blue adsorbed at the surface of $\mathrm{MgO}$ into small molecules in the initial stage. In contrast, $\cdot \mathrm{O}_{2}{ }^{-}$and $\cdot \mathrm{OH}$ played more important roles than $\mathrm{h}^{+}$in determining the degradation efficiency of methylene blue with further increase in the reaction period. According to the general view, ${ }^{78}$ photo-induced electrons could not be efficiently produced by $\mathrm{MgO}$ with a broad band gap (5.23 eV, Table 1). To our knowledge, in the photo-catalysis process, the photo-induced electrons could rapidly transfer presumably due to the presence of heterojunction in the mesocrystal flower-like MgO (Fig. 1d and e), which might promote the separation of photo-induced electrons and holes and suppress efficiently their recombination. The lower PL intensity of flower-like MgO relative to other morphologies of products (Fig. $5 \mathrm{~b}$ ) also indicated the lower recombination rate of holes and electrons. ${ }^{75,79,80}$ Therefore, flower-like $\mathrm{MgO}$ demonstrated excellent photocatalytic activity in degradation of methylene blue to $\mathrm{CO}_{2}, \mathrm{H}_{2} \mathrm{O}$ and others under UV light illustration.

\section{Conclusions}

In summary, micro-sized flower-like $\mathrm{MgO}$ particles with excellent performance in photocatalytic degradation of various organic dyes (e.g., methylene blue, Congo red, thymol blue, bromothymol blue, eriochrome black $\mathrm{T}$, and their mixture) had been successfully prepared by a facile precipitation via the reaction between $\mathrm{Mg}^{2+}$ and $\mathrm{CO}_{3}{ }^{2-}$ under a temperature of $70^{\circ} \mathrm{C}$.
Time-dependent experiments demonstrated that their formation involved a complex process, in which after the initial mixture of reactants, the product was prone to turn into agglomerates or rod-like particles with a formula of $x \mathrm{MgCO}_{3}$ $\cdot y \mathrm{H}_{2} \mathrm{O}(x=0.75-0.77$ and $y=1.87-1.96)$. Because of the chemical instability, they would transfer into flower-like particles with a composition of $x \mathrm{MgCO}_{3} \cdot y \mathrm{Mg}(\mathrm{OH})_{2} \cdot z \mathrm{H}_{2} \mathrm{O}(x=0.84-$ $0.86, y=0.13-0.23$, and $z=0.77-1.15)$. With extension of the reaction time, the content of $\mathrm{Mg}(\mathrm{OH})_{2}$ in the product demonstrated an increasing trend, whereas an opposite tendency was observed for the level of $\mathrm{H}_{2} \mathrm{O}$. In addition, we found that the performance of the flower-like particles in photocatalytic degradation of organic dyes was superior to other morphologies of $\mathrm{MgO}$ (e.g., nest-like, spherical, rod-like and trapezoidal structures) due to the stronger adsorption ability to organic dyes. The developed catalyst also demonstrated an excellent reusability, and after five cycles the degradation efficiency could still be maintained beyond $92 \%$. The superior photocatalytic performance on the degradation of organic dyes suggested that the flower-like $\mathrm{MgO}$ was a promising candidate for environmental remediation.

\section{Conflicts of interest}

There are no conflicts to declare.

\section{Acknowledgements}

The authors would like to acknowledge funding support from the National Natural Science Foundation of China (Grant No. 21575112, 51672165, 21777128, and 21705125).

\section{References}

1 C. Fernández, M. S. Larrechi and M. P. Callao, TrAC, Trends Anal. Chem., 2010, 29, 1202-1211.

2 Z. Aksu, Process Biochem., 2005, 40, 997-1026.

3 I. M. Banat, P. Nigam, D. Singh and R. Marchant, Bioresour. Technol., 1996, 58, 217-227. 
4 A. H. Shalla, M. A. Bhat and Z. Yaseen, J. Environ. Chem. Eng., 2018, 6, 5938-5949.

5 Z. Bai, Y. Zheng and Z. Zhang, J. Mater. Chem. A, 2017, 5, 6630-6637.

6 S. Natarajan, H. C. Bajaj and R. J. Tayade, J. Environ. Sci., 2018, 65, 201-222.

7 S. Garcia-Segura and E. Brillas, J. Photochem. Photobiol., C, 2017, 31, 1-35.

8 D. Cao, Y. Wang and X. Zhao, Curr. Opin. Green Sustain. Chem., 2017, 6, 78-84.

9 F. Han, V. S. R. Kambala, M. Srinivasan, D. Rajarathnam and R. Naidu, Appl. Catal., A, 2009, 359, 25-40.

10 K. M. Lee, C. W. Lai, K. S. Ngai and J. C. Juan, Water Res., 2016, 88, 428-448.

11 B. Show, N. Mukherjee and A. Mondal, RSC Adv., 2016, 6, 75347-75358.

12 D. P. DePuccio, P. Botella, B. O'Rourke and C. C. Landry, ACS Appl. Mater. Interfaces, 2015, 7, 1987-1996.

13 K. Simeonidis, S. Mourdikoudis, E. Kaprara, M. Mitrakas and L. Polavarapu, Environ. Sci.: Water Res. Technol., 2016, 2, 43-70.

14 Z. Bai, Y. Zheng, W. Han, Y. Ji, T. Yan, Y. Tang, G. Chen and Z. Zhang, CrystEngComm, 2018, 20, 4090-4098.

15 A. Kruk, Opt. Mater., 2018, 84, 360-366.

16 Y. H. Leung, A. M. C. Ng, X. Xu, Z. Shen, L. A. Gethings, M. T. Wong, C. M. N. Chan, M. Y. Guo, Y. H. Ng, A. B. Djurišić, P. K. H. Lee, W. K. Chan, L. H. Yu, D. L. Phillips, A. P. Y. Ma and F. C. C. Leung, Small, 2014, 10, 1171-1183.

17 D. Veselý, A. Kalendová and P. Němec, Surf. Coat. Technol., 2010, 204, 2032-2037.

18 J. Shiogai, Y. Ito, T. Mitsuhashi, T. Nojima and A. Tsukazaki, Nat. Phys., 2015, 12, 42.

19 M. Y. Guo, A. M. C. Ng, F. Liu, A. B. Djurišić and W. K. Chan, Appl. Catal., B, 2011, 107, 150-157.

20 K. Mageshwari, S. S. Mali, R. Sathyamoorthy and P. S. Patil, Powder Technol., 2013, 249, 456-462.

21 R. Sathyamoorthy, K. Mageshwari, S. S. Mali, S. Priyadharshini and P. S. Patil, Ceram. Int., 2013, 39, 323330.

22 A. B. Gh, M. Sabbaghan and Z. Mirgani, Spectrochim. Acta, Part A, 2015, 137, 1286-1291.

23 K. N. S. Kumara, H. P. Nagaswarupa, K. R. V. Mahesh, S. C. Prashantha, M. Mylarappa and D. M. K. Siddeshwara, Nanosyst.: Phys., Chem., Math., 2016, 7, 662-666.

24 N. Salehifar, Z. Zarghami and M. Ramezani, Mater. Lett., 2016, 167, 226-229.

25 A. Najafi, Ceram. Int., 2017, 43, 5813-5818.

26 M. Mantilaka, R. T. De Silva, S. P. Ratnayake, G. Amaratunga and K. M. N. de Silva, Mater. Res. Bull., 2018, 99, 204-210.

27 S. Demirci, B. Öztürk, S. Yildirim, F. Bakal, M. Erol, O. Sancakoğlu, R. Yigit, E. Celik and T. Batar, Mater. Sci. Semicond. Process., 2015, 34, 154-161.

28 J. Zhao, G. Zhu, W. Huang, Z. He, X. Feng, Y. Ma, X. Dong, Q. Fan, L. Wang, Z. Hu, Y. Lü and W. Huang, J. Mater. Chem., 2012, 22, 19679-19683.
29 N. Sutradhar, A. Sinhamahapatra, S. K. Pahari, P. Pal, H. C. Bajaj, I. Mukhopadhyay and A. B. Panda, J. Phys. Chem. C, 2011, 115, 12308-12316.

30 G. Kordas, J. Mater. Chem., 2000, 10, 1157-1160.

31 Z. Zhang, Y. Zheng, J. Chen, Q. Zhang, Y. Ni and X. Liang, Adv. Funct. Mater., 2007, 17, 2447-2454.

32 Z. Zhang, Y. Zheng, Y. Ni, Z. Liu, J. Chen and X. Liang, J. Phys. Chem. B, 2006, 110, 12969-12973.

33 Z. Zhang, Y. Zheng, J. Zhang, Q. Zhang, J. Chen, Z. Liu and X. Liang, Cryst. Growth Des., 2007, 7, 337-342.

34 X. Zhang, Y. Zheng, H. Yang, Q. Wang and Z. Zhang, CrystEngComm, 2015, 17, 2642-2650.

35 Y. Zheng, X. Zhang, X. Wang, Q. Wang, Z. Bai and Z. Zhang, CrystEngComm, 2016, 18, 2612-2616.

36 Y. Zhang and J. Mu, J. Colloid Interface Sci., 2007, 309, 478484.

37 K. S. W. Sing, D. H. Everett, R. A. W. Haul, 1. Moscou, r. A. Pierotti, J. Rouquerol and T. Siemieniewska, Pure Appl. Chem., 1985, 57, 603-619.

38 S. A. Ansari, M. M. Khan, M. O. Ansaric and M. H. Cho, New J. Chem., 2016, 40, 3000-3009.

39 B. Zielińska, J. Grzechulska, R. J. Kaleńczuk and A. W. Morawski, Appl. Catal., B, 2003, 45, 293-300.

40 C. Xu, G. P. Rangaiah and X. S. Zhao, Ind. Eng. Chem. Res., 2014, 53, 14641-14649.

41 C. Yang, W. Dong, G. Cui, Y. Zhao, X. Shi, X. Xia, B. Tang and W. Wang, Sci. Rep., 2017, 7, 3973.

42 T. Chankhanittha and S. Nanan, Mater. Lett., 2018, 226, 7982.

43 S. Y. Yao, X. Zhang, F. Y. Qu, A. Umar and X. Wu, J. Alloys Compd., 2016, 689, 570-574.

44 Q. Zeng, J. Bai, J. Li, L. Xia, K. Huang, X. Li and B. Zhou, J. Mater. Chem. A, 2015, 3, 4345-4353.

45 M. Wu, Q. F. Jing, X. Y. Feng and L. M. Chen, Appl. Surf. Sci., 2018, 427, 525-532.

46 S. C. Yan, Z. S. Li and Z. G. Zou, Langmuir, 2009, 25, 1039710401.

47 W. B. White, Am. Mineral., 1971, 56, 46-53.

48 A. Botha and C. A. Strydom, Hydrometallurgy, 2001, 62, 175183.

49 J. Lanas and J. I. Alvarez, Thermochim. Acta, 2004, 421, 123132.

50 L. Xiang, F. Liu, J. Li and Y. Jin, Mater. Chem. Phys., 2004, 87, 424-429.

51 M. Sharma and P. Jeevanandam, J. Alloys Compd., 2011, 509, 7881-7885.

52 G. Wang, L. Zhang, H. Dai, J. Deng, C. Liu, H. He and C. T. Au, Inorg. Chem., 2008, 47, 4015-4022.

53 K.-H. Kim, M.-S. Lee, J.-S. Choi and J.-P. Ahn, Thin Solid Films, 2009, 517, 3995-3998.

54 V. M. Boddu, D. S. Viswanath and S. W. Maloney, J. Am. Ceram. Soc., 2008, 91, 1718-1720.

55 K. Zhu, J. Hu, C. Kübel and R. Richards, Angew. Chem., 2006, 118, 7435-7439.

56 F. Wang, N. Ta and W. Shen, Appl. Catal., A, 2014, 475, 76-81.

57 J. V. Stark and K. J. Klabunde, Chem. Mater., 1996, 8, 19131918. 
58 K. J. Klabunde, J. Stark, O. Koper, C. Mohs, D. G. Park, S. Decker, Y. Jiang, I. Lagadic and D. Zhang, J. Phys. Chem., 1996, 100, 12142-12153.

59 Y. Li and W. Shen, Chem. Soc. Rev., 2014, 43, 1543-1574.

60 J. Lian, C. Zhang, Q. Li and D. H. L. Ng, Nanoscale, 2013, 5, 11672-11678.

61 H.-B. Lu, L. Liao, H. Li, Y. Tian, D.-F. Wang, J.-C. Li, B.-P. Zhu and Y. Wu, Solid State Commun., 2008, 147, 57-60.

62 P. Wang, C. Li, H. Gong, H. Wang and J. Liu, Ceram. Int., 2011, 37, 3365-3370.

63 C. Jin, H. Kim, S. An and C. Lee, Chem. Eng. J., 2012, 198-199, 420-425.

64 S.-W. Bain, Z. Ma, Z.-M. Cui, L.-S. Zhang, F. Niu and W.-G. Song, J. Phys. Chem. C, 2008, 112, 11340-11344.

65 P. F. Wang, Z. H. Li, Y. M. Zhu, K. Gao and K. Y. Wang, J. Alloys Compd., 2010, 492, 532-535.

66 C.-Y. Cao, J. Qu, F. Wei, H. Liu and W.-G. Song, ACS Appl. Mater. Interfaces, 2012, 4, 4283-4287.

67 Y. Qu, W. Zhou, Z. Ren, K. Pan, C. Tian, Y. Liu, S. Feng, Y. Dong and H. Fu, Eur. J. Inorg. Chem., 2012, 2012, 954-960. 68 Z.-M. Cui, Z. Chen, C.-Y. Cao, W.-G. Song and L. Jiang, Chem. Commun., 2013, 49, 6093-6095.
69 J. Hou, S. Chen, C. Cao, H. Liu, C. Xiong, N. Zhang, Q. He, W. Song and Z. Nie, Rapid Commun. Mass Spectrom., 2016, 30, 208-216.

70 S. Yang, P. Huang, L. Peng, C. Cao, Y. Zhu, F. Wei, Y. Sun and W. Song, J. Mater. Chem. A, 2016, 4, 400-406.

71 J. Xu, D. Xu, B. Zhu, B. Cheng and C. Jiang, Appl. Surf. Sci., 2018, 435, 1136-1142.

72 R. Shen, C. Jiang, Q. Xiang, J. Xie and X. Li, Appl. Surf. Sci., 2019, 471, 43-87.

73 X. Li, J. Yu and M. Jaroniec, Chem. Soc. Rev., 2016, 45, 26032636.

74 W. Li, X. Geng, F. Xiao, G. An and D. Wang, ChemCatChem, 2017, 9, 3762-3771.

75 F. Wu, X. Li, W. Liu and S. Zhang, Appl. Surf. Sci., 2017, 405, 60-70.

76 Y. Xia, Q. Li, K. Lv and M. Li, Appl. Surf. Sci., 2017, 398, 81-88.

77 L. Zhang, G. Wang, Z. Xiong, H. Tang and C. Jiang, Appl. Surf. Sci., 2018, 436, 162-171.

78 N. Mao and J.-X. Jiang, Appl. Surf. Sci., 2019, 476, 144-150.

79 Y. Zhao, Y. Wang, E. Liu, J. Fan and X. Hu, Appl. Surf. Sci., 2018, 436, 854-864.

80 Y. Xu, D. Lin, X. Liu, Y. Luo, H. Xue, B. Huang, Q. Chen and Q. Qian, ChemCatChem, 2018, 10, 2496-2504. 